Chapter 17

\title{
Contemporary Surgical Management of Acute Massive Pulmonary Embolism
}

\author{
Dawn S. Hui and P. Michael McFadden \\ Additional information is available at the end of the chapter \\ http://dx.doi.org/10.5772/53969
}

\section{Introduction}

Pulmonary embolism (PE) is the most lethal pulmonary condition in the United States and internationally. It is also the third most common cause of death in hospitalized patients. Since the introduction of computed tomographic pulmonary angiography (CT-PA), the estimated incidence of PE has risen from 62.1 to 112.3 cases per 100,000 [1]. Untreated, the associated mortality of $\mathrm{PE}$ is as high as $30 \%$ with recurrent embolism being the most common cause. Globally, systemic anticoagulation is the mainstay of treatment for both chronic and acute PE. In the case of acute massive PE (presenting with hypotension and systolic arterial pressure less than $90 \mathrm{~mm} \mathrm{Hg}$ ) the prognosis is much graver and associated with a mortality of $30-60 \%$, second only to sudden cardiac death as a cause of sudden death. This condition mandates a more aggressive and urgent algorithm for diagnosis and treatment. Prompt and appropriate treatment, which may include surgical pulmonary embolectomy, can be life-saving.

\section{Historical developments}

The history of venous thrombosis and PE is intertwined with landmark developments in the disciplines of anatomy, pathology, hematology, and surgery [2]. While pathologic observations of postmortem pulmonary thrombi were detailed by Morgagni [3], Laennec [4], and Cruveilhier [5] in the 18th and 19th centuries, it was not until the late 19th century that the concept of thromboembolism was by recognized by Virchow. Virchow wrote "A plug may extend into the vena cava as thick as the last phalanx of the thumb. These are the thrombi that constitute the source of real danger; it is in them that ensues the crumbling away which 
leads to secondary occlusion in remote vessels" [6]. He was thus the first to ascribe a single pathophysiologic mechanism to these anatomically separate phenomena (Figures 1 and 2).

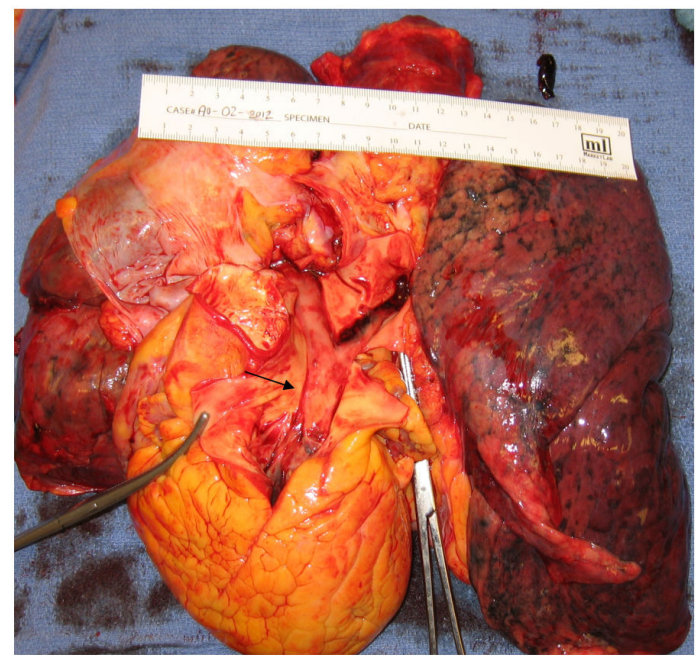

Figure 1. Autopsy photo demonstrating a sudden fatal saddle embolism which occurred six days following pulmonary lobectomy.

The surgical treatment of pulmonary embolism was first proposed by Friedrich Trendelenburg, a German professor of surgery from Leipzig. Having studied the cases of nine patients who died from acute pulmonary embolism, he developed a technique of pulmonary embolectomy through animal experimentation. His first two human patients died at 15 hours and 37 hours, from heart failure and hemorrhage of the internal mammary artery respectively [7]. Trendelenburg's student Martin Kirschner reported the first successful pulmonary embolectomy to the German Surgical Conference in Berlin in 1924 [8]. In Europe this became a popular emergent bedside operation for patients in whom PE was strongly suspected. Surgical residents were relegated to a bedside vigil and watched for sudden circulatory collapse and respiratory compromise in high-risk patients. Fewer than 10 patients survived the operation in 300 cases over a decade [2]. Though popular in Europe, the first successful pulmonary embolectomy was not reported in the United States until 1958 [9]. Operative mortality was frequently due to myocardial ischemia resulting in ventricular fibrillation and death at anesthetic induction [10]. The development of extracorporeal circulation by John Gibbon was in fact stimulated by his reflections while keeping vigil over a patient who underwent an unsuccessful attempt at pulmonary embolectomy: “...During the hours that night, John watched the patient's distended veins and recorded the faltering pulse, respirations and blood pressure, the thought occurred to him and constantly recurred to him that her conditions could surely be improved if only there were some form of continuously withdrawing some of the blue blood from the swollen veins into an apparatus where the blood could pick up oxygen and discharge carbon dioxide, and then be pumped back into the patient's arter- 
ies" [11]. This stimulated his work over the next twenty years to develop the heart-lung machine, ultimately opening the doors to modern cardiac surgery and to the first successful pulmonary embolectomy on cardiopulmonary bypass (CPB) by Edward Sharp in 1962 [10].

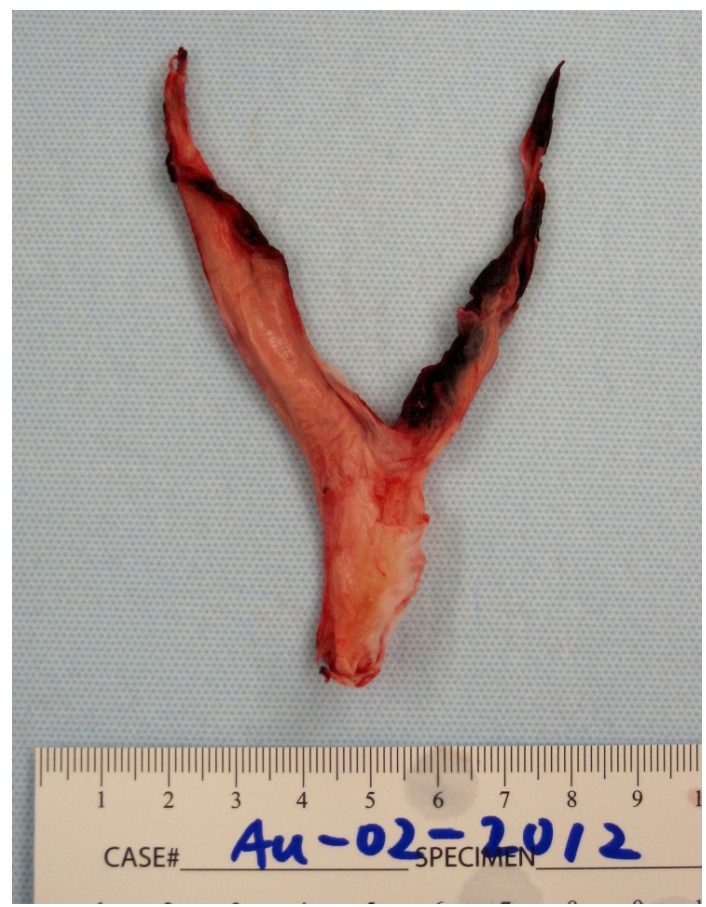

Figure 2. The saddle embolism isolated

Other surgical developments benefited from Virchow's legacy by attacking the problem at its more proximate source. The American surgeon Alton Ochsner, who had been present at Kirschner's 1924 address, proposed with Michael DeBakey to ligate the IVC in 1932 [12, 13]. John Homans, a general surgeon focused on venous disease, performed prophylactic lower extremity vein ligation [14]. Caval interruption commonly resulted in chronic lower extremity edema with the complications of varices, edema, and ulceration. As Spencer stated, "Because of the morbidity often following ligation of the vena cava, it is probably used too seldom and too late, being reserved as last resort..." [15]. Narrowing of the IVC via a right flank incision as an adjunct to pulmonary embolectomy has also been described, with the authors abandoning this technique due to impaired venous return [16]. Refinement of venous interruption came in the form of the Miles clip [17], partial caval plication, and finally percutaneous intraluminal occlusive devices (Figure 3). Early occlusive devices were hampered by complications of migration, embolization, vena cava wall rupture, and the need for femoral cutdown. Current filters have evolved in ease of insertion, lower complication rates, and efficacy with long-term patency rates of $98 \%$ and $3 \%$ recurrent embolism rates [18,19] (Figure 4). 


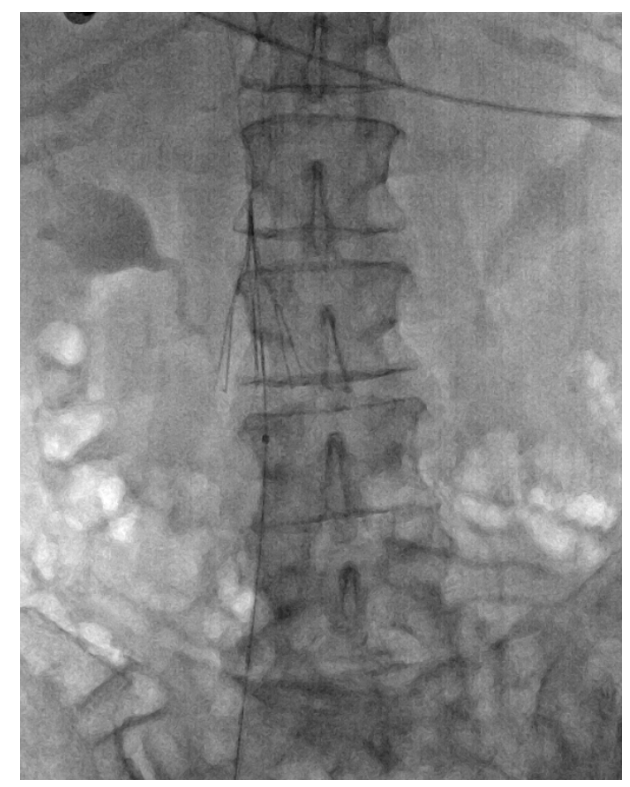

Figure 3. Vena Cava Filter.

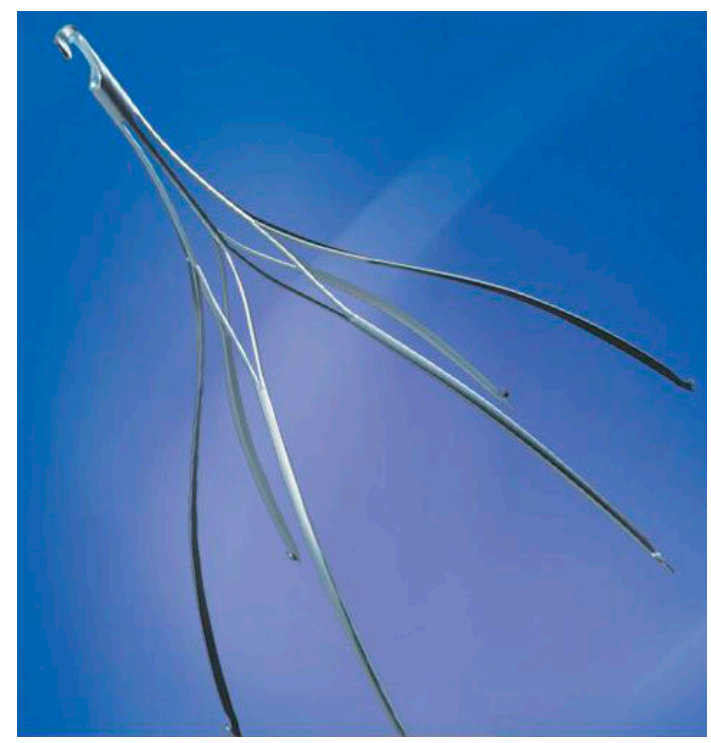

Figure 4. Nitinol Option ${ }^{\mathrm{TM}}$ Vena Cava Filter (Argon Medical Devices, Plano, TX). Features of contemporary filters include retrievability, MRI compatibility, and percutaneous insertion. 
Concurrent with the developments in surgical techniques to treat PE were discoveries in anticoagulation. Heparin, discovered by McLean [20] and validated by Murray [21], has become the workhorse of initial therapy of PE. The discovery of oral dicumerol in the 1940s has led to the use of anticoagulation as the mainstay of both prevention of and therapy for venous thrombosis and PE. The efficacy of anticoagulants, thrombolytics, and vena caval filters combined with the high mortality rate of pulmonary embolectomy, had led to a paradigm shift towards nonoperative management of acute massive PE.

\section{Contemporary management: diagnosis and prognostication}

Classification of PE was historically based on the angiographic burden, using the Miller Index [22]. Current classification by American Heart Association differentiates between massive PE (sustained hypotension for at least 15 minutes or requiring inotropic support, pulselessness, or persistent profound bradycardia) from submassive (acute PE without systemic hypotension but with either RV dysfunction or myocardial necrosis) (Table 1) [23]. Early identification and risk stratification is mandatory at the time of diagnosis in order to coordinate multimodality treatment strategies. Prompt diagnosis and initiation of treatment can reverse RV failure and reduce mortality. Current tools for prognostication include clinical parameters, radiographic findings, and laboratory markers.

\begin{tabular}{|c|c|}
\hline \multirow{4}{*}{ Massive PE } & $\begin{array}{l}\text { Acute PE with sustained hypotension (Systolic blood pressure }<90 \mathrm{~mm} \mathrm{Hg} \text { for at least } 15 \\
\text { minutes or requiring inotropic support) }\end{array}$ \\
\hline & $\begin{array}{l}\text { Not due to a cause other than PE, such as arrhythmia, hypovolemia, sepsis, or left } \\
\text { ventricular [LV] dysfunction }\end{array}$ \\
\hline & Pulselessness \\
\hline & Persistent profound bradycardia (heart rate $<40 \mathrm{bpm}$ with signs or symptoms of shock) \\
\hline \multirow{10}{*}{ Submassive PE } & $\begin{array}{l}\text { Acute PE without systemic hypotension (systolic blood pressure }<90 \mathrm{~mm} \mathrm{Hg} \text { ) but with } \\
\text { either right ventricular ( } \mathrm{RV} \text { ) dysfunction or myocardial necrosis }\end{array}$ \\
\hline & RV dysfunction means the presence of at least 1 of the following: \\
\hline & $\begin{array}{l}\text { RV dilation (apical 4-chamber RV diameter divided by LV diameter }>0.9 \text { ) or RV systolic } \\
\text { dysfunction on echocardiography }\end{array}$ \\
\hline & $\begin{array}{l}\text { RV dilation (4-chamber RV diameter divided by LV diameter }>0.9 \text { ) on computed } \\
\text { tomography }\end{array}$ \\
\hline & Elevation of beta-natriuretic peptide $(B N P>90 \mathrm{pg} / \mathrm{mL})$ \\
\hline & Elevation of $\mathrm{N}$-terminal pro-BNP $(>500 \mathrm{pg} / \mathrm{mL})$ \\
\hline & $\begin{array}{l}\text { Electrocardiographic changes (new complete or incomplete right bundle-branch block, } \\
\text { anteroseptal ST elevation or depression, or anteroseptal T-wave inversion) }\end{array}$ \\
\hline & Myocardial necrosis is defined as either of the following: \\
\hline & Elevation of troponin I $(>0.4 \mathrm{ng} / \mathrm{mL})$ or \\
\hline & Elevation of troponin $\mathrm{T}(>0.1 \mathrm{ng} / \mathrm{mL})$ \\
\hline
\end{tabular}

Table 1. American Heart Association Classification of Pulmonary Embolism [23]. 
Clinical signs consistent with major PE include transient syncope, cyanosis, elevated jugular venous pressure, tachypnea, unilateral restriction of chest wall movement, fever, and signs of RV dysfunction (Table 2).

\begin{tabular}{|c|c|}
\hline & Left parasternal heave \\
\hline & Accentuated P2 \\
\hline \multirow[t]{4}{*}{ Clinical Signs of RV dysfunction } & Murmur of tricuspid regurgitation \\
\hline & Distended neck veins \\
\hline & Unilateral restriction of chest wall \\
\hline & RBBB \\
\hline \multirow{3}{*}{$\begin{array}{l}\text { Electrocardiogram Signs of } \\
\text { Right Heart Strain }\end{array}$} & Right axis deviation \\
\hline & T-wave in V1-V4 \\
\hline & Qr pattern in V1 \\
\hline \multicolumn{2}{|l|}{$\mathrm{P} 2$ = pulmonic second heart sound } \\
\hline \multicolumn{2}{|l|}{ RBBB $=$ right bundle branch block } \\
\hline $\mathrm{RV}=$ right ventricle & \\
\hline
\end{tabular}

Table 2. Clinical and Electrocardiographic Signs of RV dysfunction [24]

Several scoring systems including the Pulmonary Embolism Severity Index [25] and Revised Geneva Score [26] have been developed based primarily on clinical signs and history (Tables $3 \& 4$ ). They have been shown to have prognostic value [23] and do not require diagnostic studies, making them a valuable tool for early prognostication.

\begin{tabular}{ll}
\hline \multicolumn{1}{c}{$\begin{array}{c}\text { Pulmonary Embolism } \\
\text { Severity Index }\end{array}$} & Score \\
\hline Age & 1 point per year \\
\hline Male Sex & 10 \\
\hline History of Cancer & 30 \\
\hline History of Heart Failure & 10 \\
\hline History of Chronic Lung Disease & 10 \\
\hline Pulse $>110$ beats/min & 20 \\
\hline Systolic Blood Pressure $<100 \mathrm{~mm} \mathrm{Hg}$ & 30 \\
\hline Respiratory Rate $>$ breaths/min & 20 \\
\hline Temperature $<35{ }^{\circ} \mathrm{C}$ & 20 \\
\hline Altered Mental Status & 60 \\
\hline Arterial oxyhemoglobin saturation level $<90 \%$ & 20 \\
\hline Class I - 65 points & $0-1.6 \%$ \\
\hline Class II - $65-85$ points & $1.7-3.5 \%$ \\
\hline Class III - 85-105 points & $3.2-7.1 \%$ \\
\hline Class IV - 106-125 points & $4.0-11.4 \%$ \\
\hline Class V - >125 points & $10.0-24.5 \%$ \\
\hline
\end{tabular}

Table 3. Pulmonary Embolism Severity Index [25] 


\begin{tabular}{|c|c|}
\hline Revised Geneva Score & Points \\
\hline Age $>65$ years & 1 \\
\hline Previous DVT or PE & 3 \\
\hline Surgery under general anesthesia or lower limb fracture within 1 month & 2 \\
\hline Active malignant condition (solid or hematologic, currently active or considered cured < 1 year) & 2 \\
\hline Unilateral lower limb pain & 3 \\
\hline Hemoptysis & 2 \\
\hline Heart rate $75-94$ beats/min & 3 \\
\hline Heart rate $>94$ beats $/ \mathrm{min}$ & 5 \\
\hline Pain on lower limb deep venous palpation and unilateral edema & 4 \\
\hline \multicolumn{2}{|l|}{ Clinical Probability } \\
\hline \multicolumn{2}{|l|}{ Low: 0 - 3 points } \\
\hline Intermediate: 4-10 points & \\
\hline
\end{tabular}

Table 4. Revised Geneva Score [26]

Biomarkers assessing the degree of right ventricular dysfunction associated with massive PE that have been studied include troponin and beta-natriuretic peptide (BNP). Right ventricular strain results in elevated troponin levels through acute shear stress causing microinjury and microinfarction, as well as increased oxygen demand and diminished perfusion from an acutely dilated and overloaded RV. Troponin levels have been found to correlate with the presence of RV dysfunction [27,28], and cutoff values for troponin prognostication in PE are identical to those in acute MI [29] while cutoff values for BNP are lower than those in congestive heart failure. Negative predictive value for both troponin and BNP are $97-100 \%$; however the positive predictive values are low, with a wide range of sensitivities and low specificity for adverse events.

While most patients with suspected PE will have computed tomography angiography of the chest, on occasion concerns for acute renal injury will prompt workup with ventilation-perfusion scans. RV enlargement, defined as RV to LV dimension ratio $>0.9$ on a reconstructed CT 4-chamber view, has been found to correlate with echocardiographic findings of RV dysfunction [30]. Subsequently, a study of 431 consecutive patients with acute PE found that RV enlargement predicted 30 -day mortality $(15.6 \%$ vs $7.7 \%$, hazard ratio 5.17$)$ as well as the composite end-point of death and in-hospital complications [31]. Dynamic CT assessment of right ventricular response to reperfusion therapy or surgical embolectomy found that although RV enlargement persisted in 43\%, significant reductions in mean RV dimension and $\mathrm{RV} / \mathrm{LV}$ ratio and significant increases in mean LV occurred with therapy, and did so equally in patients treated with thrombolysis versus embolectomy. Patients presenting with cardiogenic shock had a greater degree of initial RV enlargement and a greater reduction post- 
therapy [32]. Echocardiography may demonstrate the McConnell sign of acute pulmonary embolism, a characteristic pattern of akinesis of the mid free wall and normal motion of the apex [33]. Other signs include right ventricular hypokinesis, right ventricle dilation, and signs of pulmonary hypertension. In normotensive patients, RV dilation is present in $30-40 \%$ and predicts in-hospital mortality as well higher non-resolution and recurrence of pulmonary thrombus burden [34].

\section{Contemporary multimodality management}

While chronic conditions such as heart failure and malignancy are responsible for most of the late deaths in acute PE, early 30-day mortality results primarily from right ventricular failure [31]. Contemporary diagnostic modalities such as computed tomography and echocardiography allow for improved risk stratification and patient selection for pulmonary embolectomy, while evolution of surgical techniques has prompted a renewed enthusiasm for surgical pulmonary embolectomy as part of a multimodality approach to massive acute PE (Figure 5). The indications for open surgical embolectomy have traditionally been for clearly documented acute massive pulmonary embolism with persistent hypotension refractory to maximal pharmacological support.

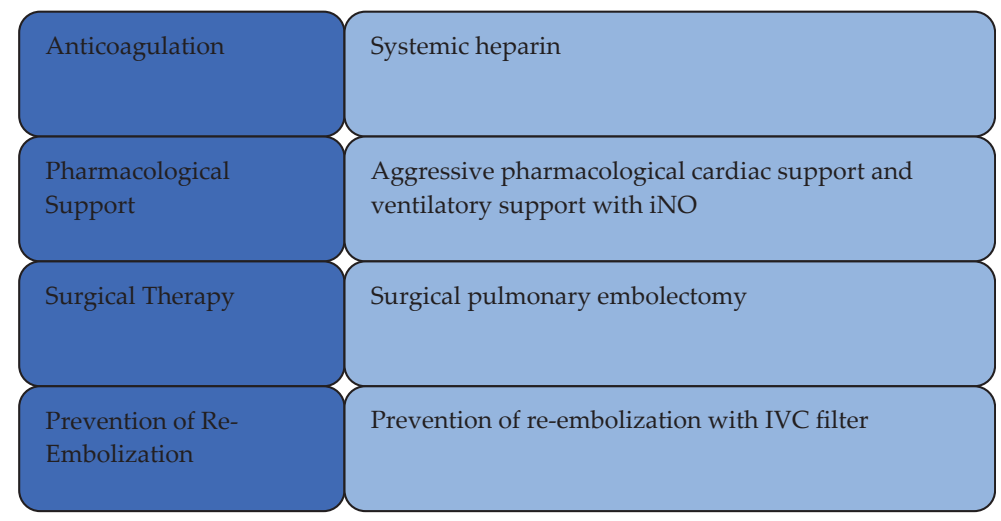

Figure 5. Contemporary multimodality approach to treatment of acute massive PE

Multimodality treatment begins with immediate systemic heparinization at diagnosis, cardiogenic support with inotropic agents and vasopressors as indicated, and correction of hypoxemia with supplemental oxygen or ventilatory support with pulmonary arterial vasodilation using inhaled nitric oxide. The underlying critical pathology is acutely elevated pulmonary vascular resistance (PVR) leading to pressure overload of the right ventricle and acute RV distention. Through ventricular interdependence, LV filling is reduced, compromising cardiac output and oxygen delivery. (Figure 6). The initial goals of medical manage- 
ment are optimization of RV preload and systolic function, reduction of pulmonary vascular resistance, and maintenance of right coronary perfusion pressure by adequate aortic root pressure [35]. Acute massive pulmonary embolism is initially a pressure overload problem of the RV. Higher filling pressures may be required; however an altered Frank-Starling curve in the setting of RV dysfunction may lead to volume overload as well. For patients with low cardiac output and normal blood pressure, modest fluid challenges may be beneficial, and the use of dobutamine and dopamine is a class IIa recommendation. Class I recommendations include correction of systemic hypotension and use of vasopressors, although the use of norepinephrine lacks clinical data, while the beneficial use of epinephrine in PE with shock has been reported [36].

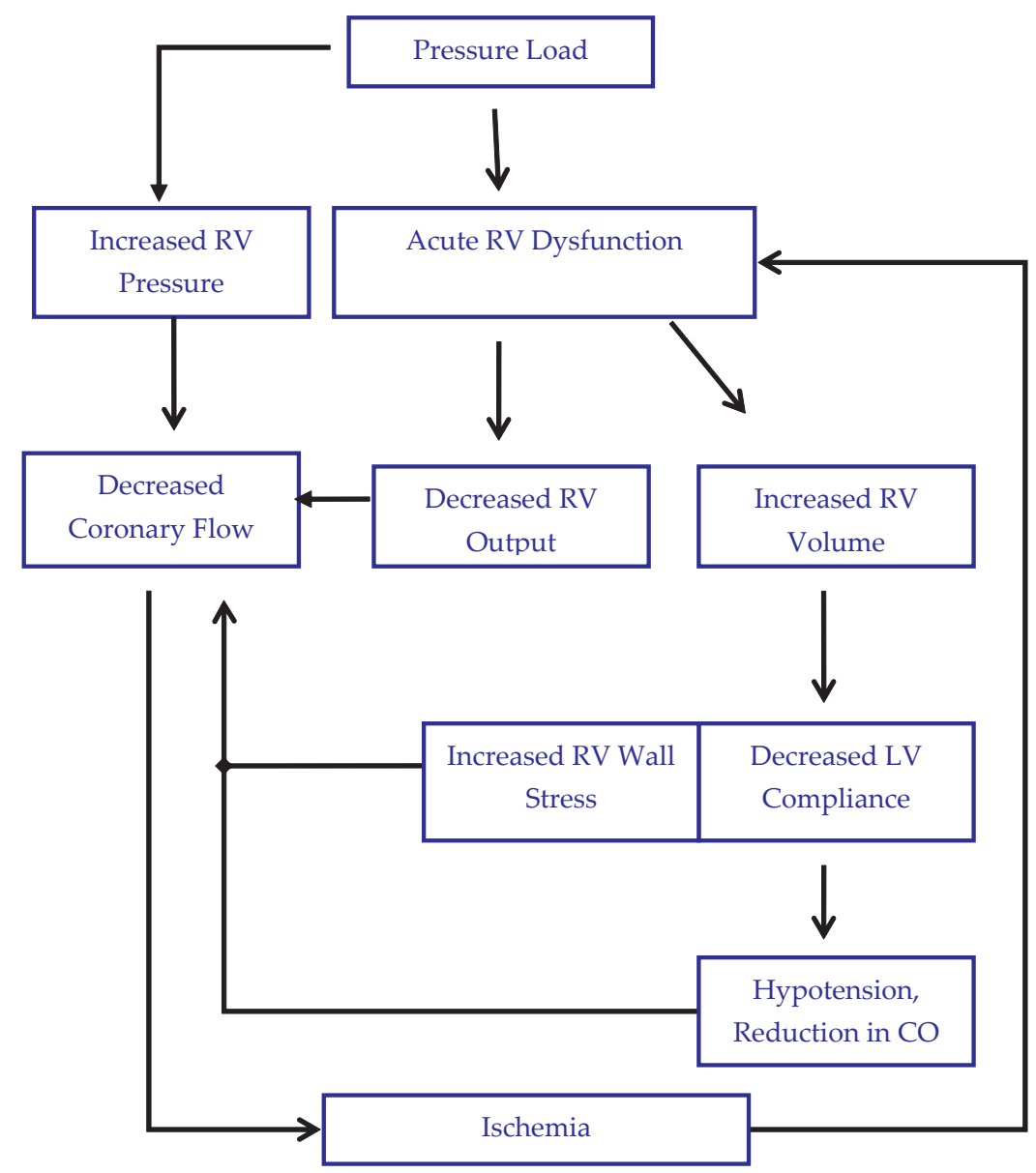

Figure 6. Hemodynamic effects of acute massive PE 
RV function is coupled to pulmonary vascular resistance. Agents to reverse elevated PVR may be intravenous, inhaled, or oral. All intravenous forms (prostacyclin, iloprost, sildenafil, milrinone, and adenosine) carry the risk of systemic hypotension and should be instituted only after resuscitation and adequate perfusion of the RV. These agents may worsen the ventilation/perfusion ratio, increasing the degree of pulmonary shunt. Inhalational agents target the therapy to well-ventilated regions of the pulmonary bed, improving V/Q ratio and decreasing shunt fraction. Inhaled nitric oxide (iNO) has been studied in ARDS, pulmonary hypertension, and post mitral valve surgery, while evidence of its use in pulmonary embolism is limited to case reports and small case series. [37, 38, 39, 40]. While controlled studies supporting its routine use as an adjunct are lacking, anecdotal evidence based on timing of the institution of iNO seems to point to reductions in mean pulmonary artery pressures, increases in arterial oxygenation, and improvement in hemodynamics [38].

\subsection{Surgical pulmonary embolectomy}

The Trendelenburg operation was performed through a second transthoracic incision with resection of the second rib, occlusion of the aorta and pulmonary artery with an encircling rubber tube, and rapid removal of the embolism through a limited arteriotomy. Occlusion was limited to "forty-five seconds to two minutes, beyond that, death occurs" [7]. Modern surgical approach is by median sternotomy. After systemic heparinization, normothermic CPB is instituted via aortic and bicaval cannulation. The vena cavae are encircled with umbilical tapes. The operation is performed either with a beating heart and vacuum-assisted venous drainage or with the heart arrested. Deep hypothermic circulatory arrest has also been used in cases to optimize visualization for complete embolectomy [41]. The cavae are snared to isolate right heart inflow. A longitudinal incision of the pulmonary trunk is made two $\mathrm{cm}$ above the pulmonary valve. The extent of pulmonary arteriotomy is tailored to the location of thrombus. The incision can be carried in a hockey-stick fashion onto the left main pulmonary artery (Figure 7). For right-sided embolectomy, the right pulmonary artery is incised between the superior vena cava and the aorta. A variety of techniques of thrombus extraction have been described. Large clot can be retrieved with Randall stone forceps, vigorous suction, and Fogarty embolectomy catheters passed into branch arteries. Opening of the bilateral pleura and manual compression of the lungs to extrude peripheral clot has been described but has the drawbacks of mechanical injury to the arterial walls and lung parenchyma, as well as possibly causing endobronchial bleeding [42].

Retrograde flushing via direct cannulation of the pulmonary veins from the left atrium has been described to remove not only residual thrombotic material but air embolism as well. As described by Zarrabi et al, if the right atrium is opened to look for suspected clot, a septal incision through the fossa is then made, the left atrium entered, and the pulmonary veins identified. A cannula is attached to the pump oxygenator, inserted into each pulmonary vein sequentially, and flushed for $60-80$ seconds with a mean pressure of $15-17 \mathrm{~mm} \mathrm{Hg}$. Clot and debris thus flushed retrograde through the pulmonary veins is extracted through the pulmonary arteriotomy [43]. If the right atrium is not entered, retrograde flushing of the left atrium can be performed via a 20 Fr cannula. This is inserted through the right superior pul- 
monary vein and attached to the arterial line through a $\mathrm{Y}$ connector [44]. Finally, adequate visualization of the distal arterial tree can be extended with use of an arterioscope. Postoperative mortality in these patients is felt to be due to eventual right ventricular failure from residual thrombus causing persistent pulmonary hypertension and interstitial pulmonary edema [41]. However, data concerning which of the above techniques is best to remove thrombus burden in the lungs, reduce RV strain, or improve outcomes is lacking. Intraoperative use of TEE during pulmonary embolectomy is recommended and can identify intrathoracic extrapulmonary thromboemboli which may alter planned surgical maneuvers [45]. Reflecting back towards the original Trendelenburg procedure, inflow occlusion pulmonary embolectomy is an option where CPB is not immediately available. This technique consists of caval occlusion for 3-minute maximal periods, beyond which there is great risk of cardiac and neurologic complications [46].

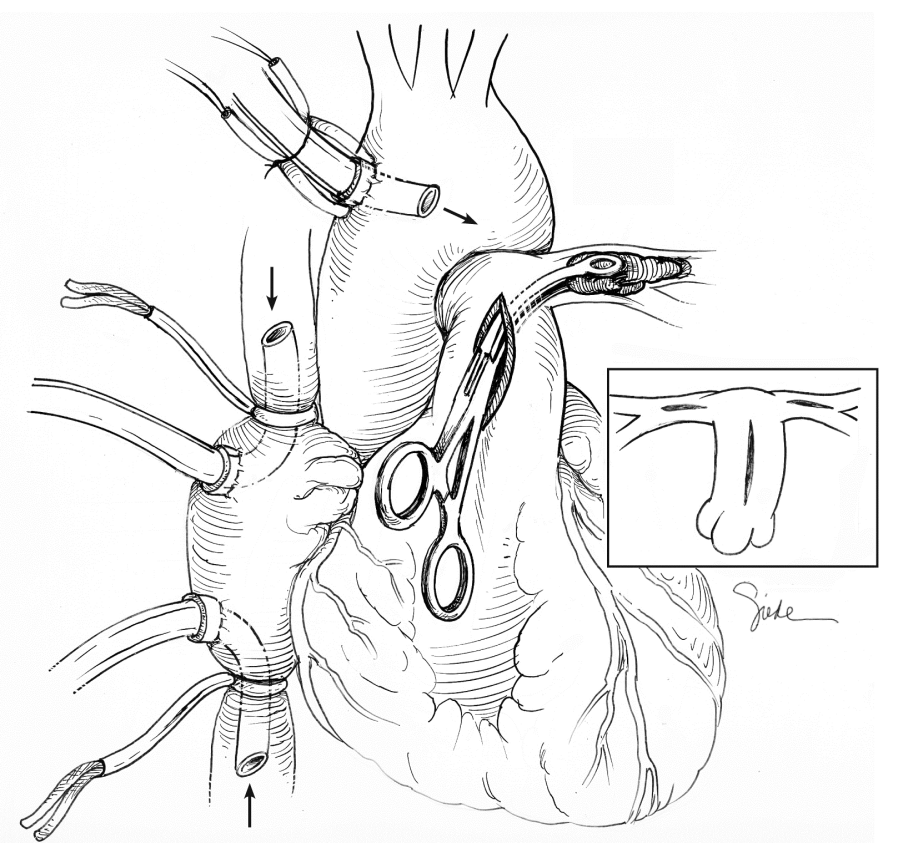

Figure 7. Technique of cardiopulmonary bypass with bicaval cannulation, arrows indicating direction of blood flow. Randall stone forceps are inserted through the main pulmonary arteriotomy to extract a portion of embolus from the left pulmonary artery. Inset: The three arteriotomy sites: main pulmonary artery, left and right pulmonary arteries

\subsection{Contemporary surgical outcomes and expanded indications}

A systematic review of pulmonary embolectomies in the period from 1961 to 2006 showed the average mortality to be $30 \%$. Several important factors in mortality included the time period, with higher mortality reported in studies before 1985 (32\% vs 20\%) and in patients 
with preoperative cardiac arrest (59\% vs 29\%) [47]. Prospectively studied patients that have failed an initial course of thrombolytics have lower mortality with embolectomy than with a second course of thrombolysis ( $7 \%$ vs. 38\%) [48]. More recent studies have begun to examine results in patients not meeting strict criteria of sustained hypotension or cardiogenic shock, but rather using evidence of RV dysfunction as an expanded criteria for pulmonary embolectomy, with operative mortality in contemporary series being 6-8\% [49-53]. Expediency of operation has also found to have improved outcomes, particularly with surgical therapy occurring within 24 hours of diagnosis [54]. The improvement in operative mortality in the modern era may be due to several factors: improved patient selection, early identification of RV dysfunction with contemporary diagnostic modalities, extent of pulmonary thrombectomy to prevent residual thrombus and thus pulmonary hypertension, the prophylactic use of IVC filters, and early operation before the development of cardiogenic shock or the need for cardiopulmonary resuscitation, both of which confer a significantly increased in-hospital mortality (25\% and $65 \%$, respectively vs $8.1 \%$ ) [55]. By instituting a criteria of RV dysfunction as an indication for pulmonary embolectomy, the population to be considered expands to include patients with submassive PE.

\subsection{Thrombolytics, special populations, catheter-based therapy, and IVC filters}

The benefit of thrombolytic therapy in the treatment of acute PE has been controversial. A meta-analysis showed that overall, there was no significant reduction in PE or death when comparing thrombolysis with heparin; neither was the risk of major bleeding significantly increased. Subgroup analysis showed a significant reduction in PE and death in the trials that included patients with major (i.e. hemodynamically unstable) PE and no benefit in those trials that excluded those patients [56]. A review of current evidence concluded that, "Despite the lack of a verifiable mortality benefit associated with thrombolytic therapy in patients with massive PE resulting in hemodynamic instability, most clinicians accept this clinical scenario as indication for thrombolytics and it is guideline based" [57]. In the most recent guidelines (2012), The American College of Chest Physicians evidence for thrombolytic administration is graded $2 \mathrm{C}$ for unstable patients without high bleeding risk; recommendations are against thrombolytics in stable patients (Grade 1C) [58].

Because the effects are systemic, thrombolytics poses a risk of serious perioperative bleeding and should be approached with caution in patients with acute massive PE that may be considered for surgical embolectomy.

This decision is of particular interest in populations whose underlying disease places them at increased risk of bleeding elsewhere. Trauma patients with immobility and/or traumatic brain injury are prone to DVT and PE; sites of bleeding risk include concomitant solid organ injury and intracranial hemorrhage. Reluctance to place prophylactic IVC filters has been due to filter-related complications and inconsistent follow-up; this has been tempered by more recent studies showing low complication rates and safe retrievability at greater intervals. Limited data consisting of matched-control trials have shown reduced PE and PE-related mortality rates with prophylactic filters [59]. Yet, prophylactic IVC filter placement in atrisk patients remains a Level III recommendation by the Eastern Association for the Surgery 
Trauma guidelines [60]. Increased risk of both thromboembolic disease and intracranial hemorrhage is seen also in patients with brain tumors. Successful pulmonary embolectomy has been reported in a patient with advanced glioblastoma multiforme, suggesting that this clinical scenario may represent an extended indication for surgery [61]. In patients with significant cardiac disease, pulmonary symptoms are often ascribed to cardiac etiology, but rarely concomitant PE may be discovered [62], in which case surgical pulmonary embolectomy may be combined with the operation to treat the primary cardiac disease.

Catheter-based techniques include aspiration thrombectomy, fragmentation, and rheolytic thrombectomy. Rheolytic thrombectomy using the AngioJet and Rotarex devices has been shown to be technically feasible with success rates of $92.2 \%$ to $100 \%$, with significant improvements in both angiographic indices and clinical indices (i.e, Miller Index, obstruction index, perfusion index, mean pulmonary artery pressures, partial arterial pressures) [63, 64]. Data is limited to small series, and this therapy requires experienced laboratories. Its role as primary therapy is for patients with contraindications to thrombolysis, failed thrombolysis, or impending death from shock prior to thrombolysis when no other intervention is available [58].

The placement of IVC filters is prudent even after treatment with pulmonary embolectomy to prevent recurrent embolism from lower extremity sources. In several series, this has resulted in a zero recurrence rate $[53,65]$, while a $23 \%$ recurrence rate was noted in a series of patients without IVC filter placement after embolectomy [48].

\section{Conclusion}

Acute massive pulmonary embolism is a disease best treated by multimodality therapy, beginning with systemic heparinization and IVC filter placement. A multitude of diagnostic modalities, including transesophageal echocardiography and computed chest tomography, are available in the contemporary setting to guide risk-stratification and to assess RV dysfunction. Contemporary series of pulmonary embolectomy have demonstrated low operative mortality with improved surgical techniques, and survival is increased when operative therapy occurs before the development of hemodynamic collapse. Thus, the modified Trendelenburg procedure with extended distal pulmonary embolectomy should be part of an aggressive approach to an otherwise lethal problem in the current age.

\section{Author details}

Dawn S. Hui and P. Michael McFadden

Department of Cardiothoracic Surgery, University of Southern California Keck School of Medicine, Los Angeles, California, USA 


\section{References}

[1] Wiener RS, Schwartz LM, Woloshin S. Time trends in pulmonary embolism in the United States: evidence of overdiagnosis. Arch Intern Med. 2011;171(9):831.

[2] McFadden PM, Ochsner JL. A history of the diagnosis and treatment of venous thrombosis and pulmonary embolism. Ochsner J. 2002; 4(1): 9-13.

[3] Westaby S. The foundations of cardiac surgery. In: Landmarks in cardiac surgery. Oxford, UK: Isis Medical Meia; 1997. p. 1-47.

[4] Laennec RTH. De l'auscultation medicale ou traité du diagnostic des maladies des poumons et du couer. Paris, France: Brossen et Claude; 1819.

[5] Cruveilhier J. Anatomie pathologique du corps humain: ou description, avec figures lithographiées et colorieés, des diverses alterations morbides dont le corps humain est susceptible. Paris, France: JB Bailliere; 1829-1842.

[6] Virchow R. Die cellularpathologic in ihrer begrudung auf physiologische und gewebelehre. Berlin, Germany: A Hirschwald; 1858).

[7] Trendelenburg F. General surgery, pathology and therapy. I. Operative interference in embolism of the pulmonary artery. Annals of Surgery 1908 Nov; 48 (5): 772-786.

[8] Kirschner M. Ein durch die trendelenburgsche operation geheilter fall von bolie der arterien pulmonalis. Arch Klin Chir. 1924; 133:312.

[9] Steenburg, RW, R. Warren, R E Wilson, and Le Rudolf: A new look at pulmonary embolectomy. Surg., Gynec \& Obst.1958; 107:214.

[10] Sharp EH. Pulmonary embolectomy: successful removal of a massive pulmonary embolus with the support of cardiopulmonary bypass - case report. Annals of Surgery 1962; 156(1): 1-4.

[11] Litwak, R.S. The growth of cardiac surgery: historical notes. Cardiovascular Clinics 1971; 3: 5-50.

[12] Ochsner A, Ochsner JL, Sanders HS. Prevention of pulmonary embolism by caval ligation. Ann Surg 1970; 171: 923-938.

[13] Ochsner A, Ochsner JL. Prevention of pulmonary embolism. Milit Med 1971; 136: 829-835.

[14] Homans J. Thrombosis of deep veins of the lower leg, causing pulmonary embolism. New Engl J Med 1934; 211: 993-997.

[15] Spencer FC, Quattlebaum JK, Sharp EH, Jude JR. Plication of the inferior vena cava for pulmonary embolism: a report of 20 cases. Annals of Surgery 1962; 155(6): 827-35.

[16] Blake DB. Pulmonary embolectomy re-evaluated. Ann Royal College of Surgeons of England 1981; 63: 18-24. 
[17] Miles RM, Chappell F, Renner O. A partially occluding caval clip for the prevention of pulmonary embolism. Am Surg 1964; 30: 40-47.

[18] Greenfield LJ, Zocco J, Wilk J, Schroeder TM, Elkins RC. Clinical experience with the Kim-Ray Greenfield vena cava filter. Ann Surg 2977; 185: 692-698.

[19] Roehm JOF Jr, Gianturco C, Barth MH, Wright KC. Percutaneous transcatheter filter for the inferior vena cava: a new device for treatment of patients with pulmonary embolism. Radiology 1984; 150: 255-257.

[20] McLean J. The thromboplastin action of cephalin. Am J Physiol 1916; 41: 250.

[21] Murray DWG, Jacques LB, Perrett TS, Best CH. Heparin and thrombosis of veins following injury. Surgery 1937; 2:163-187.

[22] Miller GA, Sutton GC, Kerr IH, Gibson RV, Honey M. Comparison of streptokinase and heparin in treatment of isolated acute massive pulmonary embolism. Br Med J. 1971; 2: 681- 684 .

[23] Jaff MR, McMurtry MS, Archer SL, Cushman M, Goldenberg NA,

[24] Goldhaber SZ, Jenkins JS, Kline JA, Michaels AD, Thistlethwaite P, Vedantham S, White RJ, Zierler BK; on behalf of the American Heart Association Council on Cardiopulmonary, Critical Care, Perioperative and Resuscitation, Council on Peripheral Vascular Disease, and Council on Arteriosclerosis, Thrombosis and Vascular Biology. Management of massive and submassive pulmonary embolism, iliofemoral deep vein thrombosis, and chronic thromboembolic pulmonary hypertension: a scientific statement from the American Heart Association. Circulation. 2011;123:1788 -1830.

[25] Goldhaber SZ. Cardiac biomarkers in pulmonary embolism. Chest 2003; 123: 1782-84.

[26] Aujesky D,Obrosky DS,Stone RA, Auble TE, Perrier A, Cornuz J et al. Derivation and validation of a prognostic model for pulmonary embolism. Am J Respir Crit Care Med Year 2005: 172 (8); 1041-1046.

[27] Le Gal G, Righini M, Roy PM, Sanchez O, Aujesky D, Bounameaux H, Perrier A. Prediction of pulmonary embolism in the emergency department: the revised Geneva score. Ann Intern Med. 2006 Feb 7;144(3):165-71.

[28] Meyer T, Binder L, Hruska N, Luthe H, Buchwald AB. Cardiac troponin I elevation in acute pulmonary embolism is associated with right ventricular dysfunction. JACC 2000; 36: 1632-1636

[29] Giannitsis E, Muller-Bardorff M, Kurowski V, Weidtmann B, Wiegand U, Kaampmann M, Katus HA. Independent prognostic value of cardiac troponin $\mathrm{T}$ in patients with confirmed pulmonary embolism. Circulation. 2000;102:211-217.

[30] Piazza G, Goldhaber SZ. The acutely decompensated right ventricle: pathways for diagnosis and management. Chest 2005; 128 (3): 1836-1852. 
[31] Quiroz R, Kucher N, Schopef UJ, Kipfmueller F, Solomon SD, Costello P, Goldhaber SZ. Right ventricular enlargement on chest computed tomography: prognostic role in acute pulmonary embolism. Circulation 2004; 109: 2160-2167.

[32] Schoepf JU, Kucher N, Kipfmueller F, Quiroz R, Costello P, Goldhaber SZ. RV enlargement on chest computed tomography: a predictor of early death in acute pulmonary embolism. Circ 2004; 110: 3276-80

[33] Kipfmueller F, Quiroz R, Goldhaber SZ, Schoepf UJ,Costello P, Kucher N. Chest CT assessment following thrombolysis or surgical embolectomy for acute pulmonary embolism. Vasc Med 2005; 10; 85-89.

[34] McConnell MV, Solomon SD, Rayan ME, Come PC, Goldhaber SZ, Lee RT. Regional right ventricular dysfunction detected by echocardiography in acute pulmonary embolism. Am J Cardiol. 1996; 78: 469-473.

[35] Masotti L, Righini M, Vuilleumier N, Antonelli F, Landini G, Cappelli R, Ray P. Prognostic stratification of acute pulmonary embolism: focus on clinical aspects, imaging, and biomarkers. Vasc Health Risk Manag. 2009; 5: 567-575.

[36] Price LC, Wort SJ, Finney SJ, Marino PS, Brett SJ. Pulmonary vascular and right ventricular dysfunction in adult critical care: current and emerging options for management: a systematic literature review. Critical Care 2010; 14(5): R169

[37] Guidelines on the diagnosis and management of acute pulmonary embolism: The Task Force for the Diagnosis and Management of Acute Pulmonary Embolism of the European Society of Cardiology (ESC) Eur Heart J (2008) 29(18): 2276-2315. doi: 10.1093/eurheartj/ehn310

[38] Capellier G, Jacques T, Balvay P, Blasco G, Belle E, Baralle F. Inhaled nitric oxide in patients with pulmonary embolism. Intensive Care Med 23: 1089-1092.

[39] Szold O, Khoury W, Biderman P, Klausner JM, Halper P, Weinbroum AA. Inhaled nitric oxide improves pulmonary functions following massive pulmonary embolism: a report of four patients and review of the literature. 2006 Lung 184: 1-5.

[40] Schenk P, Mittermayer C, Ratheiser K. Inhaled nitric oxide in a patient with severe pulmonary embolism. Ann Emerg Med 1999; 33: 710-714.

[41] Trummer G, Berchtold-Herz M, Martin J, Beyersdoff F. Successful treatment of pulmonary hypertension with inhaled nitric oxide after pulmonary embolectomy. Ann Thoracic Surg 2002; 73: 1299-1301.

[42] Van Putte BP, Bantal N, Snijder R, Morshuis WJ, Van Boven W-J. Interact CardioVasc Thorac Surg 2008 (7): 412-414.

[43] Kadner A, Schmidli, Schönhoff F, Krähenbühl E, Immer F, Carrel T, Eckstein F. Excellent outcome after surgical treatment of massive pulmonary embolism in critically ill patients. JTCVS 2008 Aug; 136: 448-51. 
[44] Zarrabia K, Yarmohammadi H, Ostova MA. Retrograde pulmonary embolectomy in massive pulmonary embolism. Eur J Cardiothorac Surg 2005; 28(6): 897-899.

[45] Spagnolo S, Grasso MA, Tesler UF. Retrograde pulmonary perfusion improves results in pulmonary embolectomy for massive pumonary embolism. Tex Heart Inst J. 2006; 33: 473-6.

[46] Rosenberger P, Shernan SK, Mihaljevic T, Eltzschig HK. Transesophageal echocardiography for detecting extrapulmonary thrombi during pulmonary embolectomy. Ann Thoracic Surg 2004; 78: 862-866.

[47] Bobadilla J, Wigfield CH, Chopra PS. Inflow occlusion pulmonary embolectomy in the modern era of cardiac surgery. J Thorac Cardiovasc Surg 2006;131:484-486.

[48] Stein PD, Alnas M, Beemath A, Patel NR. Outcome of pulmonary embolectomy. Am J Cardiol 2007; 99: 421-423.

[49] Meneveau N, Séronde M, Blonde M, Legalery P, Didier-Petit K, Briand F et al. Management of unsuccessful thrombolysis in acute massive pulmonary embolism. Chest 2006; 129: 1043-1050.

[50] Yalamanchili K, Fleisher AG, Lehrman SG, Axelrod HI, Lafaro RJ, Sarabu MR et al. Open pulmonary embolectomy for treatment of major pulmonary embolism. Ann Thorac Surg 2004; 77: 819-23.

[51] Carvalho EM, Macedo FIB, Panos AL, Ricci M, Salerno TA. Pulmonary embolectomy: recommendation for early surgical intervention. J Card Surg 2010; 25:261-26.

[52] Leacche M, Unic D, Goldhaber SZ, Rawn JD, Aranki SF, Couper GS et al. Modern surgical treatment of massive pulmonary embolism: results in 47 consecutive patients after rapid diagnosis and aggressive surgical approach. JTCVS 2005; 129:1018-23.

[53] Aklog L, Williams CS, Byrne JG, Goldhaber SZ. Acute pulmonary embolectomy: a contemporary approach. Circ 2002; 105:1415-1419.

[54] Sareyyupoglu B, Greason KL, Suri RM, Keegan MT, Dearani JA, Sundt TM. A more aggressive approach to emergency embolectomy for acute pulmonary embolism. Mayo Clin Proc 2010; 85 (9): 785-790.

[55] Ahmed P, Khan AA, Smith A, Pagala M, Abrol S, Cunningham JN, Vaynblat M. Expedient pulmonary embolectomy for acute pulmonary embolism: improved outcomes. Interact CardioVasc Thorac Surg 2008; 7: 591-4.

[56] Kasper W, Konstantinides S, Geibel A, Olschewski M, Heinrich F, Grosser KD, Rauber K, Iversen S, Redecker M, Kienast J. Management strategies and determinants of outcome in acute major pulmonary embolism: results of a multicenter registry. J Am Coll Cardiol. 1997;30:1165-1171. 
[57] Wan S, Quinlan DJ, Agnelli G, Eikelboom JW. Thrombolysis compared with heparin for the intial treatment of pulmonary embolism: a meta-analysis of the randomized controlled trials. Circ 2004; 110: 744-749.

[58] Todd JL, Tapson VF. Thrombolytic therapy for acute pulmonary embolism: a critical appraisial. Chest 2009; 135: 1321-1329.

[59] Kearon C, Akl EA, Comerota AJ, Prandoni P, Bounameaux H, Goldhaber SZ, et al. Antithrombotic therapy for VTE disease: antithrombotic therapy and prevention of thrombosis, 9th ed: American College of Chest Physicians evidence-based clinical practice guidelines. Chest 2012 Feb; 141 (2 Suppl): e419s-494s.

[60] Kidane B, Madani AM, Vogt K, Girotti M, Maltaner RA, Parry NG. The use of prophylactic inferior vena cava filters in trauma patients: a systematic review. Injury 2012; 43: 542-547.

[61] Rogers FB, Cipolle MD, Velmahos G, Rozycki G, Luchette FA. Practice management guidelines for the prevention of venous thromboembolism in trauma patients: the EAST practice management guidelines work group. J Trauma 2002; 53: 142-64.

[62] Firstenberg MS, Blais D, Abel E, Newton HB, Crestanello J. Emergent pulmonary embolectomy and advanced glioblastoma multiforme. Case Reports in Medicine 2010: 2010: 862028.

[63] Firstenberg MS, Abel E, Higgins RA, Sirak JH, Sai-Sudhakar CB, Kilic A, Crestanello J. Shortness of breath: pulmonary embolism, ischemic heart failure, or both? The role of concomitant surgery. The Heart Surgery Forum 2012; 15: E56-58.

[64] Chechi T, Vecchio S, Spaziani G, Giuliani G, Giannotti F, Arcangeli C, et al. Rheolytic thrombectomy in patients with massive and submassive acute pulmonary embolism. Catheterization and Cardiovascular Interventions 2009; 73: 506-513.

[65] Liu S, Shi HB, Gu JP, Yang ZQ, Chen L, Lou WS, et al. Massive pulmonary embolism: treatment with the Rotarex thromboectomy system. Cardiovasc Intervent Radiol 20101 Feb; 34(10): 106-113.

[66] Kucher N, Rossi E, De Rosa M, Goldhaber ASZ. Massive pulmonary embolism. Circulation 2006; 113 (4): 577-582. 